\title{
Visceral Part of the Peritoneum
}

National Cancer Institute

\section{Source}

National Cancer Institute. Visceral Part of the Peritoneum. NCI Thesaurus. Code C33880.

The serous membrane that covers the surface of all org ans located in the peritoneal cavity. 